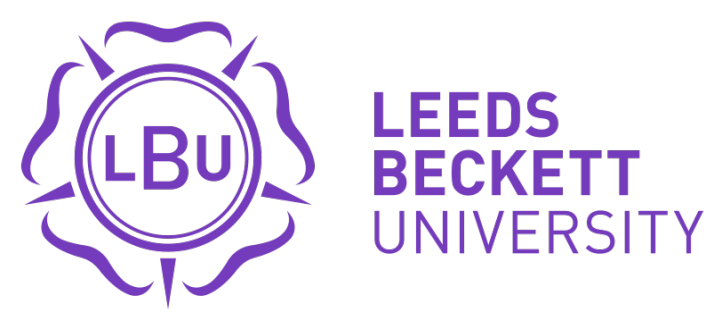

Citation:

Price, OJ and Hull, JH and Backer, V and Hostrup, M and Ansley, L (2014) The impact of exercise-induced bronchoconstriction on athletic performance: a systematic review. Sports medicine (Auckland, N.Z.), 44 (12). 1749 - 1761. ISSN 0112-1642 DOI: https://doi.org/10.1007/s40279-0140238-y

Link to Leeds Beckett Repository record:

https://eprints.leedsbeckett.ac.uk/id/eprint/2024/

Document Version:

Article (Updated Version)

The aim of the Leeds Beckett Repository is to provide open access to our research, as required by funder policies and permitted by publishers and copyright law.

The Leeds Beckett repository holds a wide range of publications, each of which has been checked for copyright and the relevant embargo period has been applied by the Research Services team.

We operate on a standard take-down policy. If you are the author or publisher of an output and you would like it removed from the repository, please contact us and we will investigate on a case-by-case basis.

Each thesis in the repository has been cleared where necessary by the author for third party copyright. If you would like a thesis to be removed from the repository or believe there is an issue with copyright, please contact us on openaccess@leedsbeckett.ac.uk and we will investigate on a case-by-case basis. 
Word Count: 3970. Abstract count: 205.

\section{THE IMPACT OF EXERCISE-INDUCED BRONCHOCONSTRICTION ON ATHLETIC PERFORMANCE - A SYSTEMATIC REVIEW}

Oliver J. Price ${ }^{1}$, James H. Hull ${ }^{1,2}$, Vibeke Backer ${ }^{3}$, Morten Hostrup ${ }^{3}$, Les Ansley ${ }^{1}$

${ }^{1}$ Faculty of Health and Life Sciences, Northumbria University, Newcastle upon Tyne, United Kingdom (UK).

${ }^{2}$ Department of Respiratory Medicine, Royal Brompton Hospital, UK.

${ }^{3}$ Department of Respiratory Medicine, Bispebjerg University Hospital, Copenhagen, Denmark.

\section{Corresponding author:}

Dr. Les Ansley

Faculty of Health and Life Sciences, Northumbria University,

Newcastle, NE1 8ST.

Tel: + 441912437773

Email: les.ansley@northumbria.ac.uk

Running title: Exercise-induced bronchoconstriction and athletic performance. 


\section{ABSTRACT}

Background: Exercise-induced bronchoconstriction (EIB) describes the phenomenon of transient airway narrowing in association with physical activity. Although it may seem likely that EIB would have a detrimental impact on athletic performance this has yet to be established. Objectives: Therefore, the aim of this review is to provide a systematic appraisal of the current status of knowledge regarding EIB and exercise performance and to highlight potential mechanisms by which performance may be compromised by EIB. Data sources and study selection: PubMed/Medline and EBSCO databases were searched up to May 2014 using the search parameter: [('exercise' OR 'athlete') AND ('asthma' OR 'bronchoconstriction' OR 'hypersensitivity') AND 'performance']. This search string returned 243 citations. After systematically reviewing all of the abstracts, 101 duplicate papers were removed, with 132 papers excluded for not including an exercise performance outcome measure. Results: The remaining ten studies that met the initial criteria were included in this review; six evaluated the performance of physically active individuals with asthma and/or EIB while four assessed the effects of medication on performance in a comparable population. Conclusion: The evidence concludes that whilst it is reasonable to suspect that EIB does impact athletic performance, there is currently insufficient evidence to provide a definitive answer.

\section{Key points:}

- Further work is required to establish the impact of exercise-induced bronchoconstriction on athletic performance.

- Future studies should address the impact of sport-specific protocols that are conducted in provocative environments.

- Disease severity and athletic standard need to be accounted for in the interpretation of future results. 


\section{BACKGROUND}

At the London 2012 Summer Olympic Games, first and third place across all athletic track events were separated by $1 \%$ of the winner's time [1]. Tiny margins decide success in elite sport and any small impingement on the ability of an athlete to perform maximally can affect competition outcome.

The capacity of the cardiovascular system is generally considered to be the limiting factor underpinning peak aerobic exercise performance [2], whilst in contrast the respiratory system is usually regarded as over-engineered for the demands during intense exercise [3].

Despite this, it is now established that a significant proportion of elite athletes exhibit an 'abnormal' airway response to intense exercise exposure. More specifically, up to half of certain cohorts of elite athletes such as swimmers and cross country skiers, appear to develop a post exercise transient narrowing of the airways [4]. This phenomenon, termed exerciseinduced bronchoconstriction (EIB), can occur either in the presence or absence of other characteristic features of asthma [5]. Indeed, EIB in elite athletes has a distinct pathogenesis and athletes frequently exceed normal resting lung function [6]. Moreover it is common to encounter athletes with a significant reduction in lung function post exercise who perceive few respiratory symptoms.

It is now recognised that endurance athletes are susceptible to the development of airway dysfunction yet still win a disproportionately high percentage of Olympic medals [7, 8]. However, there is currently a dearth of scientific literature specifically addressing the impact of EIB on exercise performance. Although several studies have aimed to address this, many fail to account for key confounding factors. For instance, studies permitting a warm-up prior to exercise potentially initiates a refractory period resulting in significantly less severe or an absence of airway narrowing $[9,10]$. 
Therefore, the aim of this review is to provide an overview of the current status of research in this field, characterize potential mechanisms by which EIB may impact exercise performance and provide recommendations for future research.

\section{METHODS}

A systematic evaluation of peer-reviewed literature from the PubMed/Medline and EBSCO databases was performed from January 1980 until May 2014 using the search parameter: [('exercise' OR 'athlete') AND ('asthma' OR 'bronchoconstriction' OR 'hypersensitivity') AND 'performance'] (English and humans (Filter), loattrfull text (Filter), not review (Filter) AND has abstract (Filter). This initial search returned 243 papers. Two authors independently reviewed the titles and abstracts of potential studies and subsequently screened full-text study reports for inclusion. After systematically reviewing the literature, 101 duplicate papers were removed, with 132 papers excluded for not including an exercise performance outcome measure (Figure 1).

As research addressing the impact of EIB on exercise performance in elite athletes is relatively limited, individuals regularly participating in sport and/or physical activity were considered further. Included studies required subjects to have a previous physician diagnosis of asthma and/or objective evidence of EIB (i.e. $\geq 10 \%$ fall in $\mathrm{FEV}_{1}$ ) following bronchoprovocation testing. Consequently, ten papers met the initial criteria; six purported to evaluate exercise performance in physically active individuals with asthma and/or EIB [11-16] while four assessed the effects of medication on performance in a comparable population [17-20]. These will be considered in more detail in the subsequent sections and form the basis of this review (Table 1). Furthermore, an appraisal of evidence using the Grading of Recommendations, Assessment, Development, and Evaluation (GRADE) [21] approach has been provided (Table 2). 


\section{RESULTS}

\subsection{DOES EIB IMPACT ON ATHLETIC PERFORMANCE?}

The limitations to performance during sport are dependent on the nature of the exercise being undertaken. It is unlikely that EIB would affect athletic performance during an event lasting $<1 \mathrm{~min}$. However, during exercise of longer duration and with specific aerobic demands, an abnormal airway response could impede performance.

\subsection{Maximal oxygen consumption}

When evaluating an individual's potential to perform successfully in endurance sport, maximal oxygen consumption $\left(\mathrm{VO}_{2 \max }\right)$ is often used as a surrogate measure for aerobic or cardiovascular capacity. As $\mathrm{VO}_{2 \max }$ is a good differentiator of aerobic performance in a heterogeneous group of individuals it is often used to characterize general athletic ability, i.e. $\mathrm{VO}_{2 \max }$ for a male individual of average athletic ability is $\sim 45 \mathrm{~mL} \cdot \mathrm{kg}^{-1} \cdot \mathrm{min}^{-1}$ and it is unusual to encounter elite level endurance athletes with a $\mathrm{VO}_{2 \max }<65 \mathrm{~mL} \cdot \mathrm{kg}^{-1} \cdot \mathrm{min}^{-1}$.

It has been argued that, in asthmatic athletes, $\mathrm{VO}_{2 \max }$ may be limited by factors other than cardiovascular capacity; i.e. by processes that slow the delivery of oxygen such as persistent airway narrowing, alveolar wall thickening and loss of elastic recoil. Certainly adult patients with severe asthma have reduced aerobic capacity [22] and asthmatic children appear to have a lower $\mathrm{VO}_{2 \max }$ and running performance than their non-asthmatic peers [23].

Despite this, Freeman et al. [14] reported that asthmatic athletes with moderate severity disease (i.e. $\mathrm{FEV}_{1}<50 \%$ ) can still achieve a high $\mathrm{VO}_{2 \max }\left(\right.$ i.e. $>60 \mathrm{~mL} \cdot \mathrm{kg}^{-1} \cdot \mathrm{min}^{-1}$ ). Moreover, crosssectional studies show no significant differences in $\mathrm{VO}_{2 \max }$ between asthmatic and nonasthmatic runners $[11,13]$. Indeed, some studies report higher $\mathrm{VO}_{2 \max }$ in elite-trained asthmatic cyclists, when compared with non-asthmatic cyclists [24].

However, the environment in which exercise is performed is important in the context of EIB. Stensrud et al. $[15,16]$ found that $\mathrm{VO}_{2 \max }$ and peak running speed $\left(\mathrm{V}_{\text {peak }}\right)$ was approximately 
5\% greater in adults with EIB (mean $\mathrm{VO}_{2 \max } 49 \mathrm{~mL} \mathrm{~kg}^{-1} \mathrm{~min}^{-1}$ ) exercising in a humid environment $\left(19.9^{\circ} \mathrm{C}\right.$ and $95 \%$ relative humidity) when compared to results obtained when exercising in standard ambient conditions $\left(20.2^{\circ} \mathrm{C}\right.$ and $40 \%$ relative humidity) [16]. Moreover, $\mathrm{VO}_{2 \max }$ and running performance was reduced by $6.5 \%$ in subjects with EIB exercising in a cold environment $\left(-18^{\circ} \mathrm{C}\right.$ and $39.2 \%$ relative humidity) [15]. Whilst these studies provide some evidence to suggest EIB has a deleterious impact on exercise performance, it is important to note that the study population was replicated, thus limiting the strength of evidence. Furthermore, a decrease in the endurance time of healthy physically active subjects has been observed during exercise in similar environmental conditions [25]. Moreover, the protocol employed was neither a traditional incremental exercise test nor a performance trial; running speed was set "by a combination of $95 \%$ of estimated maximum heart rate and the test leader's evaluation of exhaustion after eight min" $[15,16]$. Finally, athletes recruited for this study were well below the level expected for elite or competitive athletes (mean $\mathrm{VO}_{2 \mathrm{max}}$ : $48 \mathrm{~mL}^{\mathrm{kg}}{ }^{-1} \mathrm{~min}^{-}$ $\left.{ }^{1}\right)$. Indeed, only one study has examined $\mathrm{VO}_{2 \max }$ in a cohort of subjects with EIB who could truly be considered of competitive athletic ability. Teixeira et al. [11] reported no difference in peak oxygen consumption determined by treadmill ramp protocol between untreated EIB positive (mean $\mathrm{VO}_{2 \max }: 63 \mathrm{~mL} \mathrm{~kg}^{-1} \cdot \mathrm{min}^{-1}$ ) and $\mathrm{EIB}$ negative (mean $\mathrm{VO}_{2 \text { max }}: 64 \mathrm{~mL} \mathrm{~kg}^{-1} \mathrm{~min}^{-1}$ ) marathon runners.

This similarity in peak $\mathrm{VO}_{2 \max }$ between subjects with and without EIB is consistent with an earlier retrospective cohort study conducted in $(n=137)$ army recruits [12] where no difference in baseline $\mathrm{VO}_{2 \max }$ was observed between EIB positive and EIB negative groups. Moreover, performance in a two-mile time trial was not different between groups with both displaying similar features of athletic adaptation to the eight-week training programme.

In contrast to aerobic exercise, there have been no studies to date that address anaerobic capacity in athletes with EIB. Whilst Kippelen et al [26] reported no difference in $\mathrm{VO}_{2}$ kinetics 
between recreationally active EIB positive and trained negative controls during high-intensity exercise, no evidence is currently available in elite athletes.

\subsection{Performance trials}

Although $\mathrm{VO}_{2 \max }$ is a good predictor of aerobic exercise performance in the general population, the value of $\mathrm{VO}_{2 \max }$ in differentiating performance in a homogenous group of elite athletes is relatively limited [27]. This is likely due to contributing factors such as exercise, efficiency and motivation.

Several limitations arise from using an incremental or maximal exercise test as a performance outcome measure in trained athletes; specifically, the fact that the nature of the test does not reflect the demands of the sporting event.

Similar to Dickinson et al. [28], we have previously observed a significant improvement in lung function following the administration of inhaled salbutamol $(400 \mu \mathrm{g})$ versus placebo in elite soccer players $(n=11)$ with asymptomatic EIB, however no difference was detected in multiple sprint times between trials [29]. In agreement, Kalsen et al. [30] observed similar findings in elite swimmers.

Furthermore, a recent study by Koch et al. [20] addressed the effects of administering $400 \mu \mathrm{g}$ salbutamol on lung function, respiratory parameters and a $10 \mathrm{~km}$ time-trial performance in 49 trained cyclists $\left(\mathrm{VO}_{2 \max }\right.$ range: $\left.53-85 \mathrm{~mL}^{-1} \cdot \mathrm{min}^{-1}\right)$ with $(n=14)$ and without $(n=25)$ EIB. They observed that although salbutamol improved resting lung function in both groups, no difference in performance or perception of effort was detected.

Whilst it is acknowledged that the evidence to date is extremely limited, there is no published data to suggest that EIB limits sport-specific exercise performance. 


\section{MECHANISMS BY WHICH EIB MIGHT IMPACT PERFORMANCE}

There are a number of mechanisms by which bronchoconstriction may hypothetically impede athletic performance, however, if there is an impact then this likely arises due to the interplay between several factors (Figure 2).

\subsection{Exercise airflow limitation}

In both healthy and asthmatic individuals, a bronchodilatory response has been shown to occur with the onset of exercise [31]. However, it is unlikely that mild bronchodilation is of great significance in subjects susceptible to substantial bronchoconstriction (i.e. $\geq 25 \%$ fall in FEV $\mathrm{FE}_{1}$ ). In the context of EIB, airflow obstruction and symptoms classically develop in the period (e.g. 5-10 minutes) following exercise. Therefore, it has often been argued that EIB does not impact on in-exercise airflow and therefore is not relevant to exercise performance.

During exercise in healthy subjects, peak expiratory flow occurs close to the middle of the expiratory phase of respiration and there is a mild reduction in end-expiratory lung volume (EELV). However, in elite athletes who achieve high levels of ventilation there is evidence of encroachment of the tidal flow loop on the superimposed forced expiratory flow-limb. Moreover EELV may approach or surpass resting functional residual capacity (Figure 3). In recreationally active asthmatic individuals, Haverkamp et al. [32] reported an increase in average pulmonary resistance for the entire exercise duration and for the majority of subjects, expiratory flow limitation was evident. Furthermore, others have shown that EELV increases in exercising asthmatics [33].

Whilst it is accepted that limitations exist in the current methodology and techniques available to evaluate the impact of in-exercise airflow limitation [34], it seems possible that changes in maximum expiratory flow volume during exercise may influence airflow and the perception of dyspnoea experienced by athletes with EIB, as they adopt ventilatory strategies to overcome this constraint. 


\subsection{Increased work and oxygen cost of respiratory muscles}

During exercise in healthy subjects, the oxygen consumption of respiratory muscles accounts for $5-10 \%$ of whole body oxygen consumption [35]. However, alterations in EELV, ventilation-perfusion ratio and airway calibre alter the work, and therefore oxygen consumption of the respiratory muscles [36].

In support of this concept, Aaron et al. [35] observed that the oxygen cost of breathing increases to $15 \%$ of total oxygen consumption in the presence of severe expiratory airflow limitation. This increased effort of breathing and associated oxygen cost has two potential consequences for exercise performance. Firstly, to drive a higher overall oxygen cost for a given external work load and secondly to potentially drive an earlier onset of respiratory muscle fatigue [37]. Increased respiratory muscle loading may also have a deleterious impact on exercise performance via the 'respiratory muscle metaboreflex' [38]. Strenuous exercise $(>80 \%$ $\mathrm{VO}_{2 \max }$ ) in healthy individuals is associated with a reduction of diaphragmatic force following supra-maximal motor nerve stimulation-indicative of diaphragmatic muscle fatigue. This in turn may increase sympathetic vasoconstrictor outflow, reducing skeletal muscle blood flow [38]. It has been suggested that the restricted blood flow augments locomotor muscle fatigue and limits exercise capacity [37].

Furthermore, the recruitment of accessory respiratory muscles with diaphragmatic muscle fatigue has been shown to distort the chest wall and reduce the mechanical efficiency of breathing [37]. Therefore transient bronchoconstriction may increase respiratory muscle work during exercise resulting in respiratory muscle fatigue, compromised breathing efficiency and reduced oxygen availability to the working limb musculature.

\subsection{Dyspnoea and perception of effort}

Dyspnoea describes "a subjective experience of breathing discomfort that consists of qualitatively distinct sensations that vary in intensity", however the precise genesis is complex 
and remains incompletely understood [39]. It is now established that perceived exertion modulates exercise performance in healthy individuals and that the cues for sensation of perceived exertion are distinct from those of sense of effort [40]. Ventilation appears to be an important contributor to perceived exertion during exercise particularly at higher intensities [41].

It is postulated that dyspnoea begins with a physiological impairment (i.e. airway dysfunction), that leads to stimulation of pulmonary and extra-pulmonary afferent receptors; leading to afferent feedback where an uncomfortable or unpleasant sensation is perceived (i.e. chest tightness) [42]. More specifically, the sensation of dyspnoea may represent a conscious awareness of outgoing respiratory motor command. As the brainstem or motor cortex provides efferent commands to the ventilatory muscles a copy of this command is sent to the sensory cortex. The exchange between the motor and sensory cortex is termed 'corollary discharge' and is thought to be the mechanism by which conscious perception of effort arises [43]. This exchange has been proposed to determine the severity of dyspnoea and perception of effort during exercise. It is now possible to obtain surrogate indices of ventilatory drive and load imbalance [44] that can be used to characterize dyspnoea. Therefore it seems reasonable to posit that any condition that disproportionally increases the effort of breathing to the ventilatory load during exercise will amplify the perception of exertion causing premature termination of the exercise bout or a moderation of the intensity at which the exercise is performed.

To date, only one study has addressed the impact of inhaled short acting beta2-agonists versus placebo on central nervous system parameters [45]. Whilst no differences were observed on psychometric visual analogue scales and psychomotor performance tests between treatments, the cohort consisted of non-asthmatic trained triathletes $(n=23)$ (mean $\mathrm{VO}_{2 \max }: 58 \mathrm{~mL} \mathrm{~kg}^{-}$ ${ }^{1} \cdot \mathrm{min}^{-1}$ ) rather than asthmatic subjects. 


\subsection{Ventilation/perfusion mismatch}

It is well recognised that a significant proportion (up to a third in some series) of healthy trained endurance athletes exhibit exercise-induced arterial hypoxemia (EIAH); i.e. a drop in oxygen saturation defined as mild $93-95 \%$ (or 3-4\% <rest), moderate $88-93 \%$, or severe $<88 \%$ [46]. Haverkamp et al. [32] demonstrated EIAH during high-intensity exercise in physically active asthmatics (mean $\mathrm{VO}_{2 \max }: 48 \mathrm{~mL} \mathrm{~kg}^{-1} \mathrm{~min}^{-1}$ ). The decreased effectiveness of gas exchange in this population may be a result of airway inflammation in both the airways and alveolar areas leading to a poorer alveolar ventilation-perfusion ratio, smooth muscle constriction, mucosal and interstitial oedema with infiltration and closing of the small airways [32].

Munoz et al. have previously demonstrated that in mild asthmatics, EIB provokes a greater ventilation-perfusion imbalance. They proposed that this is primarily due to post exercise increases in minute ventilation and cardiac output, benefiting partial pressure of oxygen in arterial blood. In addition, ventilation-perfusion imbalance likely reflects uneven airway narrowing and blood flow redistribution generating unique ventilation-perfusion patterns including the development of areas with low and high ventilation-perfusion ratios [47]. Consequently, depending on severity, EIB may cause ventilation-perfusion imbalance and may impair the respective uptake and elimination of $\mathrm{O}_{2}$ and $\mathrm{CO}_{2}$ into and from the blood.

\section{EIB TREATMENT AND IMPACT ON PERFORMANCE}

A significant amount of research has been conducted over the past two decades investigating how asthma treatment may impact on athletic performance. This is extremely pertinent given the fact approximately one fifth of swimmers and cyclists used beta2-agonists at the Summer Olympic Games in 2004 and 2008 [7].

It is now well established that pharmacological (e.g. inhaled corticosteroids in combination with a pre-exercise inhaled beta-2-agonists and if required leukotriene receptor antagonist / mast cell stabiliser) and possibly non-pharmacological interventions (e.g. fish oil 
supplementation) are effective in protecting against airway constriction [48]. However, the mainstay of treatment for protection against EIB is the administration of an inhaled short acting beta2-agonist (e.g. salbutamol) 15 minutes prior to exercise [49].

\subsection{Impact of medication in non-asthmatic athletes}

Bedi et al. suggested that inhaled albuterol may provide a competitive advantage for nonasthmatic athletes resulting in speculation that beta-2 agonists are performance enhancing [50]. However, research to date provides little evidence that inhaled beta2-agonists in prescribed doses provide performance benefits in non-asthmatic subjects [51]. A recent systematic review and meta-analysis confirmed that no significant effects were detected for inhaled beta2agonists on endurance, strength or sprint performance in healthy athletes. However, it was highlighted that systemic beta2-agonists may elicit positive effects on physical performance, although the quality of evidence is not currently sufficient to provide a definitive answer [52]. In contrast, clenbuterol is now prohibited by the World Anti-Doping Agency (WADA) given the anabolic effects associated with treatment [53].

In a sport-specific context, Sporer et al. [54] observed no effects of $800 \mu \mathrm{g}$ salbutamol on 20$\mathrm{km}$ time-trial performance in healthy elite cyclists (mean $\mathrm{VO}_{2 \max }: 67 \mathrm{~mL} \mathrm{~kg}^{-1} \mathrm{~min}^{-1}$ ).

In contrast, some researchers have observed performance benefit; Van Baak et al [55] reported that $800 \mu \mathrm{g}$ salbutamol significantly improved time-trial performance in well-trained amateur non-asthmatic male cyclists and triathletes $(n=16)$ by $1.9 \pm 1.8 \%(\mathrm{P}<0.05)$. However, lung function increased significantly following administration of salbutamol versus placebo suggesting some of the subjects may have had undiagnosed airway obstruction. More recently, Decorte et al. [56] observed an increase in muscular endurance following the inhalation of 800 $\mu \mathrm{g}$ salbutamol. Similarly, Kalsen et al. [30] showed an improvement in arm ergometer sprint performance and muscle strength following the inhalation of high doses of beta2-agonists in elite swimmers with and without airway hyperresponsiveness. 


\subsection{Impact of medication in asthmatic athletes}

In asthmatic men (mean $\mathrm{VO}_{2 \max }: 43 \mathrm{~mL} \mathrm{~kg}^{-1} \mathrm{~min}^{-1}$ ) Freeman et al. [19] observed no improvements in performance during progressive exercise following nebulization of $5 \mathrm{mg}$ of salbutamol despite a significant increase in resting and post-exercise FEV 1 [19]. Similarly, Ingemann-Hansen [57] showed no benefits of salbutamol on $\mathrm{VO}_{2 \max }$ or endurance time to exhaustion within a comparable population.

In contrast, the administration of montelukast, a leukotriene antagonist, has been shown to improve physical performance and oxygen pulse while reducing the perception of strain at maximal workloads $[17,18]$. However, the subjects recruited in these studies were only moderately trained individuals (mean $\mathrm{VO}_{2 \max }: 44 \mathrm{~mL} \cdot \mathrm{kg}^{-1} \cdot \mathrm{min}^{-1}$ ) and even at fatigue did not attain a maximal perception of effort score. Thus it is difficult to extrapolate these findings to elite athletic performance.

\subsection{Impact of supra-therapeutic medication doses}

In non-asthmatic athletes, Dickinson et al. recently observed no effect on endurance, strength or power performance following 6-weeks $1600 \mu \mathrm{g}$ inhaled salbutamol (WADA daily upper limit) [58]. Furthermore, no significant improvement in $5 \mathrm{~km}$ time-trial performance was observed following one dose $1600 \mu \mathrm{g}$ salbutamol in a comparable population [59]. Irrespective of the aforementioned findings, information is currently relatively limited regarding the effect of asthma medication administered at supra-therapeutic doses. Indeed long-term use of high doses of beta2-agonists have been shown to be highly anabolic in several animal studies and increase muscle strength in human studies [60] however this effect has yet to be investigated following chronic use of inhaled beta2-agonists. Potentially, very high doses of inhaled beta2agonists provide the same performance-enhancing effects observed after oral ingestion [61]. 


\section{DISCUSSION}

\subsection{Does EIB impact athletic performance?}

This review reveals that it is not currently possible to draw a definitive conclusion as to whether EIB impacts athletic performance. Several methodological limitations contribute to this conclusion.

Firstly, the experimental designs of studies conducted to date have failed to adequately address the difficulties of studying athletic performance. $\mathrm{VO}_{2 \max }$ is consistently reported as the primary outcome measure however the fact that $\mathrm{VO}_{2 \max }$ is a poor predictor of athletic performance is often overlooked and sport-specific protocols are more appropriate. For instance, a high proportion of elite cyclists administer beta-2 agonists [7] as an ergogenic aid, yet any performance impact of this treatment will not be adequately detected by an indoor ramp exercise test.

In the very few studies that have employed a sport-specific challenge, EIB does not appear to impact performance [20]. However, it certainly appears that noxious environmental conditions (i.e. cold dry air) inhibit maximal aerobic capacity $[15,16]$. However, this has yet to be determined in a sport-specific challenge.

Secondly, the athletic level of subjects varies significantly between studies. This point is highlighted throughout this review whereby athletic ability, as determined by $\mathrm{VO}_{2}$ max ranges from $40-80 \mathrm{~mL}^{-1} \mathrm{~kg}^{-1} \mathrm{~min}^{-1}$; i.e. from recreationally active to elite level. The sustained ventilatory demand between elite and amateur events differs significantly. When considering exercise hyperpnoea is a key determinant of bronchoconstriction in susceptible individuals, extrapolating data derived from amateur or recreational athletes to the elite level is clearly not appropriate.

Thirdly, it is unclear whether the research to date has examined the best outcome measure. In this review we highlight the fact that central regulation (i.e. the central governor [40]) is a key 
component dictating peak athletic performance. It is therefore important to note that studies to date have focused on physiological surrogates of performance rather than central outputs / measures of performance impediment such as rating of perceived exertion during exercise tasks.

\subsection{Why do asthmatic athletes appear to outperform non-asthmatic elite athletes?}

Elite level athletes with airway dysfunction have consistently been shown to outperform their healthy peers. However as this review highlights, there is no evidence that inhaled beta-2agonists enhance athletic performance.

Explanations for this disparity proposed include the fact that physiological changes / demands associated with EIB may represent an 'extra' training stimulus that non-asthmatic athletes do not experience [7]. Others have suggested that airway dysfunction develops in elite athletes throughout the course of their careers by virtue of greater training volume in conjunction with chronic exposure to noxious environmental conditions [4] (i.e. those with EIB may have trained harder and longer to gain a competitive advantage). Finally, the development of EIB may allow mechanical advantages in certain sports such as hyperinflation resulting in improved buoyancy and reduced drag co-efficient in swimmers.

\subsection{Recommendations for future research}

Further work is needed to explore the impact of EIB on athletic performance, with due consideration of the methodological issues mentioned. More specifically, it is vital that the design of future studies addresses the impact of sport-specific protocols that are conducted in provocative environments and in a homogenous population of athletes. Outcome measures should incorporate metrics of central respiratory drive and the perception of dyspnoea, which is likely to be relevant and pertinent to performance at the elite level. Moreover, further work is needed to explore the physiological consequences of EIB and asthma medication on in- 
exercise pulmonary performance in sport-specific environments (i.e. using novel techniques of airflow limitation).

Finally, athletes included in future studies, should have a similar severity of disease. The degree of impairment to exercise performance is likely to be less in athletes with mild EIB (10 - 25\% fall in $\mathrm{FEV}_{1}$ ) when compared to athletes with more severe airflow limitation. This is relevant in the context of athletic groups 'screened' for EIB, many of whom have a mildly positive result to a bronchoprovocation test (e.g. eucapnic voluntary hyperpnoea) and in whom treatment recommendations may be made on the underlying premise that this will 'improve' their performance [62].

\section{CONCLUSION}

In conclusion, the development of EIB may have a deleterious impact on respiratory function during peak exercise however the underlying mechanisms and nature of this impediment remain to be determined. Whilst it is intuitive that EIB, when untreated, has a detrimental impact on elite athletic performance, this has not been established in the literature. Therefore, future work needs to establish the impact of bronchoconstriction on athletic performance and the development of treatment strategies to overcome this potential limitation. 


\section{TABLE HEADINGS}

Table 1. Studies evaluating the consequences of exercise-induced bronchoconstriction on exercise performance parameters.

Table 2. Studies appraised using the Grading of Recommendations, Assessment, Development, and Evaluation (GRADE) criteria [21]. 


\section{Table 1.}

\begin{tabular}{|c|c|c|c|c|}
\hline First Author / Year & Population & Diagnosis & Methodology & Summary of findings \\
\hline Performance & & & & \\
\hline Freeman et al. 1990 [13] & $\begin{array}{l}\text { Non-asthmatic endurance } \\
\text { trained runners }(n=4) ; \text { mean } \pm \\
\mathrm{SD} \mathrm{VO}_{2 \max }: 66 \pm 11 \mathrm{~mL} \cdot \mathrm{kg}^{-} \\
{ }^{1} \cdot \mathrm{min}^{-1}\end{array}$ & Physician diagnosed asthma & $\begin{array}{l}\text { Maximal treadmill exercise challenge } \\
\text { Incremental exercise challenge } \\
\text { 2-hr constant run at } 70 \% \mathrm{VO}_{2 \max }\end{array}$ & $\begin{array}{l}\text { No differences observed in } \mathrm{VO}_{2 \max } \text { or running speed } \\
\text { between asthmatic and non-asthmatic runners } \\
(\mathrm{P}>0.05)\end{array}$ \\
\hline Freeman et al.1990 [14] & $\begin{array}{l}\text { Asthmatic endurance trained } \\
\text { runners }(n=16) ; \text { mean } \pm \mathrm{SD} \\
\mathrm{VO}_{2 \max }: 63 \pm 6 \mathrm{~mL} \cdot \mathrm{kg}^{-1} \cdot \mathrm{min}^{-1}\end{array}$ & Physician diagnosed asthma & $\begin{array}{l}\text { Maximal treadmill exercise challenge } \\
\text { Sub-maximal treadmill exercise } \\
\text { challenge }\end{array}$ & $\begin{array}{l}\text { Mild to moderate asthmatics can achieve high } \\
\mathrm{VO}_{2 \max } \text { values comparable to healthy individuals } \\
\text { Severe asthma may inhibit } \mathrm{VO}_{2 \max }\end{array}$ \\
\hline Sonna et al. 2001 [12] & $\begin{array}{l}\text { US Army recruits }(n=137) \\
\text { mean } \pm \mathrm{SD} \mathrm{VO}_{2 \max }: 46 \pm 1 \\
\mathrm{~mL} \cdot \mathrm{kg}^{-1} \cdot \mathrm{min}^{-1}\end{array}$ & $\begin{array}{l}\text { Maximal treadmill exercise challenge } \\
\text { EIB definition: } \geq 15 \% \text { fall in } \mathrm{FEV}_{1} \text { post } \\
\text { challenge }\end{array}$ & 8-week basic Army training course & $\begin{array}{l}7 \% \text { of the US Army recuits were diagnosed with } \\
\text { EIB } \\
\text { EIB did not hinder physical performance gains } \\
\text { during basic training }\end{array}$ \\
\hline Stensrud et al. 2006 [16] & $\begin{array}{l}\text { Patients with objective evidence } \\
\text { of } \operatorname{EIB}(n=20) ; \text { mean } \mathrm{VO}_{2 \max } \text { : } \\
47 \mathrm{~mL} \cdot \mathrm{kg}^{-1} \cdot \mathrm{min}^{-1}\end{array}$ & $\begin{array}{l}\text { Maximal treadmill exercise challenge } \\
\text { EIB definition: } \geq 10 \% \text { fall in } \mathrm{FEV}_{1} \text { post } \\
\text { challenge }\end{array}$ & $\begin{array}{l}\text { Maximal treadmill exercise challenge } \\
\text { Warm environment }\left(19.9^{\circ} \mathrm{C} \text { and } 95 \%\right. \\
\text { relative humidity) }\end{array}$ & $\begin{array}{l}\text { Exercising in a humid environment improved } \\
\mathrm{VO}_{2 \max } \text { and } \mathrm{V}_{\text {peak }} \text { in subjects with } \mathrm{EIB}(\mathrm{P}<0.05)\end{array}$ \\
\hline Stensrud et al. 2007 [15] & $\begin{array}{l}\text { Patients with objective evidence } \\
\text { of } \mathrm{EIB}(n=20) \text {; mean } \mathrm{VO}_{2 \max } \text { : } \\
48 \mathrm{~mL} \mathrm{~kg}^{-1} \cdot \mathrm{min}^{-1}\end{array}$ & $\begin{array}{l}\text { Maximal treadmill exercise challenge } \\
\text { EIB criteria: }>10 \% \text { fall in } \mathrm{FEV}_{1} \text { post } \\
\text { challenge }\end{array}$ & $\begin{array}{l}\text { Maximal treadmill exercise challenge } \\
\text { Environment: Ambient conditions } \\
\left(20.2^{\circ} \mathrm{C} \text { and } 40 \% \text { relative humidity); }\right. \\
\text { Cold environment }\left(-18^{\circ} \mathrm{C} \text { and } 39.2 \%\right. \\
\text { relative humidity). }\end{array}$ & $\begin{array}{l}\text { Exercising in a cold environment decreased } \mathrm{VO}_{2 \max } \\
\text { and running speed in subjects with } \mathrm{EIB}(\mathrm{P}<0.05)\end{array}$ \\
\hline
\end{tabular}


Teixeira et al. 2012 [11] Elite long-distance runners $(n=$ $20)$; mean $\pm \mathrm{SD} \mathrm{VO}_{2 \max }: 64 \pm 6$ $\mathrm{mL} \cdot \mathrm{kg}^{-1} \cdot \mathrm{min}^{-1}$

\section{Medication}

Freeman et al. 1989 [19] Asthmatic patients $(n=8)$; mean $\pm \mathrm{SD} \mathrm{VO}_{2 \max }: 43 \pm 9$ $\mathrm{mL} \cdot \mathrm{kg}^{-1} \cdot \mathrm{min}^{-1}$

Non-asthmatic controls $(n=8)$; mean $\pm \mathrm{SD} \mathrm{VO}_{2 \max }: 41 \pm 6$ $\mathrm{mL} \cdot \mathrm{kg}^{-1} \cdot \mathrm{min}^{-1}$

Steinshamn et al. 2002 [17]

Asthmatic patients with EIB ( $n$ $=16$ ); mean $\pm \mathrm{SD} \mathrm{VO}_{2 \max }: 45 \pm$ $8 \mathrm{~mL} \cdot \mathrm{kg}^{-1} \cdot \mathrm{min}^{-1}$

Treadmill exercise challenge

EIB definition : $\geq 12 \%$ fall in $\mathrm{FEV}_{1}$ post challenge

Treadmill exercise challenge

Asthmatic patients with EIB ( $=18$ ); mean $\pm \mathrm{SD} \mathrm{VO}_{2 \max }: 48 \pm$ $11 \mathrm{~mL} \cdot \mathrm{kg}^{-1} \cdot \mathrm{min}^{-1}$

[18]

Koch et al. 2013 [20]

Cyclists with EIB $(n=14)$; mean $\pm \mathrm{SD} \mathrm{VO}_{2 \max }: 65 \pm 5$ $\mathrm{mL} \cdot \mathrm{kg}^{-1} \cdot \mathrm{min}^{-1}$

Cyclists without EIB $(n=35)$; mean $\pm \mathrm{SD} \mathrm{VO}_{2 \max }: 66 \pm 7$ $\mathrm{mL} \cdot \mathrm{kg}^{-1} \cdot \mathrm{min}^{-1}$

EIB definition $: \geq 12 \%$ fall in $\mathrm{FEV}_{1}$ post challenge

Eucapnic voluntary hyperpnea challenge challenge
Eucapnic voluntary hyperpnea challenge

EIB definition: $\geq 10 \%$ fall in $\mathrm{FEV}_{1}$ post challenge

Physician diagnosed asthma

$5 \mathrm{mg}$ nebulised salbutamol or saline placebo administered before a

maximal exercise challenge performed on a bicycle ergometer.

$25 \%$ athletes diagnosed with EIB

No difference was observed in $\mathrm{VO}_{2 \max }$ between athletes with and without EIB

No difference in maximal workload or $\mathrm{VO}_{2 \max }$ during exercise after salbutamol compared with placebo in asthmatic subjects $(\mathrm{P}>0.05)$

Maximal incremental exercise

Montelukast reduced maximum post- exercise fall in challenge was performed in ambient, FEV $_{1}(\mathrm{P}<0.01)$

sub-zero temperatures

$\left(-15^{\circ} \mathrm{C}\right)$.

Montelukast has a beneficial effect on physical performance in most adults with EIB

$10 \mathrm{mg} /$ day montelukast or placebo was adminstered over a 5-day period prior to the test.

Protocol replicated previous methods [17].

Montelukast: $10 \mathrm{mg} /$ day or salmeterol: $50 \mu \mathrm{g}$ over a 5 day period.

$10 \mathrm{~km}$ time-trials $60 \mathrm{~min}$ after the administration of either $400 \mu \mathrm{g}$ salbutamol or $400 \mu \mathrm{g}$ placebo.

EIB definition: $\geq 10 \%$ fall in $\mathrm{FEV}_{1}$ pos
Montelukast reduced maximum post- exercise fall in $\mathrm{FEV}_{1}$ to a greater extent than salmeterol $(\mathrm{P}<0.001)$

Montelukast may have a beneficial effect on oxygen pulse, suggesting an improved gas exchange during exercise

A significant increase in lung function was observed after the inhalation of salbutamol in comparison to placebo $(\mathrm{P}<0.001)$

Salbutamol did not effect perception of dyspnoea, leg exertion or mean power output $(\mathrm{P}>0.05)$

The increase in lung function following the inhalation of salbutamol did not translate into an increase in $10 \mathrm{~km}$ time-trial performance

EIB, Exercise-induced bronchoconstriction; $\mathbf{V O}_{2 \max }$, maximal oxygen consumption; Vpeak, peak running speed; $\mathbf{F E V} \mathbf{V}_{\mathbf{1}}$, forced expiratory volume in one second. 
Table 2.

\begin{tabular}{|c|c|c|c|c|c|c|c|}
\hline First Author / Year & Design & Limitations & Inconsistency & Indirectness & Imprecision & Other considerations & $\begin{array}{l}\text { Overall } \\
\text { quality }\end{array}$ \\
\hline \multicolumn{8}{|l|}{ Performance } \\
\hline Freeman et al. 1990 [63] & Observational & $\begin{array}{l}\mathrm{VO}_{2 \max } \text { is a poor predictor } \\
\text { of athletic performance } \\
\text { Severity of airway } \\
\text { obstruction not defined }\end{array}$ & $\begin{array}{l}\text { No important } \\
\text { inconsistencies }\end{array}$ & $\begin{array}{l}\text { Asthmatic subjects } \\
\text { recruited rather } \\
\text { than individuals } \\
\text { with objective } \\
\text { evidence of EIB } \\
\\
\text { Standard of } \\
\text { asthmatic subjects } \\
\text { below standard } \\
\text { expected for elite or } \\
\text { competitive athletes } \\
(\text { mean } \pm \text { SD } \\
\mathrm{VO}_{2 m a x} 56 \pm 5 \\
\left.\mathrm{~mL}^{-1} \mathrm{~kg}^{-1} \mathrm{~min}^{-1}\right)\end{array}$ & $\begin{array}{l}\text { Low subject } \\
\text { numbers }\end{array}$ & No further considerations & Very low \\
\hline Freeman et al. 1990 [14] & Observational & $\begin{array}{l}\text { No control group employed } \\
\mathrm{VO}_{2 \max } \text { is a poor predictor } \\
\text { of athletic performance } \\
\text { Severity of airway } \\
\text { obstruction not defined }\end{array}$ & $\begin{array}{l}\text { No important } \\
\text { inconsistencies }\end{array}$ & $\begin{array}{l}\text { Asthmatic subjects } \\
\text { recruited rather } \\
\text { than individuals } \\
\text { with objective } \\
\text { evidence of EIB } \\
\text { Standard of } \\
\text { asthmatic ranged } \\
\text { from recreational to } \\
\text { elite level athlete }\end{array}$ & $\begin{array}{l}\text { Low subject } \\
\text { numbers }\end{array}$ & No further considerations & Very low \\
\hline Sonna et al. 2001 [12] & Observational & $\begin{array}{l}\mathrm{VO}_{2 \max } \text { is a poor predictor } \\
\text { of athletic performance } \\
\text { Severity of EIB not defined }\end{array}$ & $\begin{array}{l}\text { No important } \\
\text { inconsistencies }\end{array}$ & $\begin{array}{l}\text { Physically active } \\
\text { army recruits rather } \\
\text { than athletes } \\
\text { Standard of } \\
\text { asthmatic subjects } \\
\text { below standard } \\
\text { expected for elite or } \\
\text { competitive athletes }\end{array}$ & $\begin{array}{l}\text { No serious } \\
\text { imprecision }\end{array}$ & No further considerations & Very low \\
\hline
\end{tabular}


Stensrud et al. 2006 [16]

Stensrud et al. 2007 [15]
Randomised control trial

Randomised control trial
Unable to blind study due to environmental conditions

No control group employed

$\mathrm{VO}_{2 \max }$ is a poor predictor of athletic performance

Severity of EIB not defined

$\begin{array}{ll}\text { Unable to blind study due } & \text { No important } \\ \text { to environmental } & \text { inconsistencies } \\ \text { conditions } & \end{array}$
conditions

No control group employed

$\mathrm{VO}_{2 \max }$ is a poor predictor of athletic performance

Study population replicated from previous findings

(Stensrud, Berntsen \&

Carlsen, 2006)

Severity of EIB not defined

$\mathrm{VO}_{2 \max }$ is a poor predictor of athletic performance

Severity of EIB not defined

\section{No important inconsistencies} Standard of asthmatic subjects below standard expected for elite or competitive athletes (mean \pm SD $\mathrm{VO}_{2 \max } 47 \mathrm{~mL} \cdot \mathrm{kg}^{-}$ ${ }^{1} \cdot \mathrm{min}^{-1}$ )

competitive athletes

${ }^{1 \cdot} \min ^{-1}$ )

\section{No serious}

imprecision

\section{Medication}

Freeman et al. 1989 [19] 
Severity of airway

obstruction not defined

Steinshamn et al. 2002 [17]

Koch et al. 2013 [20]

\section{Randomised} control trial Randomised
control trial

\section{No control group employed}

$\mathrm{VO}_{2 \max }$ is a poor predictor of athletic performance

Severity of EIB not defined than individuals

with objective

evidence of EIB

\section{Standard of}

asthmatic subjects

below standard

expected for elite or

competitive athletes

$($ mean \pm SD $43 \pm 9$

$\left.\mathrm{mL} \cdot \mathrm{kg}^{-1} \cdot \mathrm{min}^{-1}\right)$

\section{Standard of}

asthmatic subjects

No serious

imprecision

No further considerations

Very low

below standard

expected for elite or

competitive athletes

(mean \pm SD

$\mathrm{VO}_{2 \max }: 45 \pm 8$

$\left.\mathrm{mL} \cdot \mathrm{kg}^{-1} \cdot \mathrm{min}^{-1}\right)$

\section{No important} inconsistencie

\section{Standard of}

asthmatic subjects

below standard

expected for elite or

competitive athletes

(mean $\pm \mathrm{SD}$

$\mathrm{VO}_{2 \max }: 48 \pm 11$

$\left.\mathrm{mL} \cdot \mathrm{kg}^{-1} \cdot \min ^{-1}\right)$
No serious

imprecision

No further considerations

Very low
Randomised control trial
Severity of EIB not defined No important inconsistencies
Direct

No serious imprecision
No further considerations

Moderate

EIB, Exercise-induced bronchoconstriction; $\mathbf{V O}_{2 \max }$, maximal oxygen consumption. 


\section{FIGURE HEADINGS}

Figure 1. PRISMA flow chart representing search results.

Figure 2. Proposed schematic depicting how exercise-induced bronchoconstriction may impact exercise performance.

Figure 3. Maximal flow-volume loops during incremental maximal exercise: (a) endurance athlete without expiratory flow limitation; (b) endurance athlete with objective evidence of bronchoconstriction. 


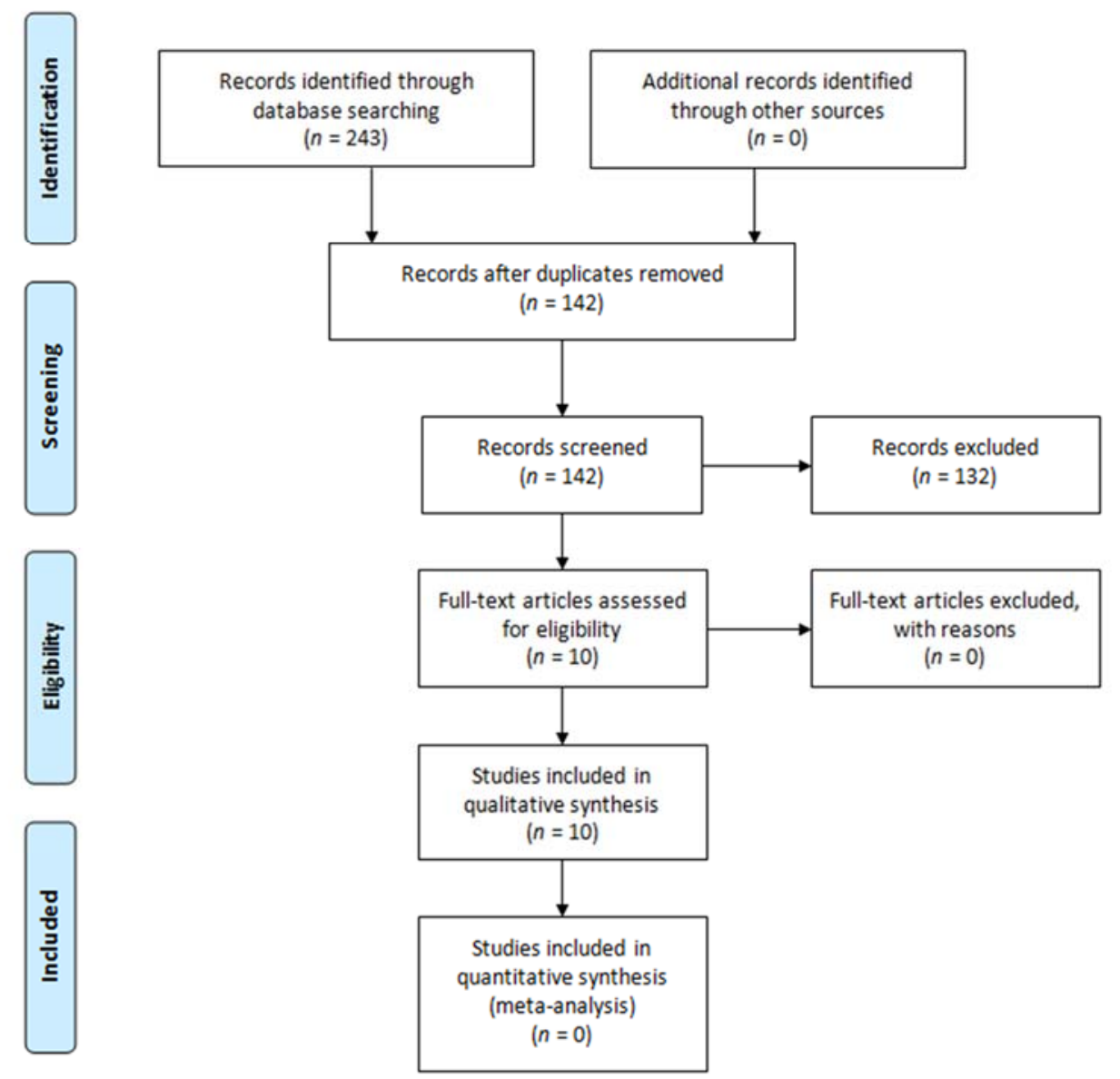

Figure 1. 
Exercise-induced bronchoconstriction

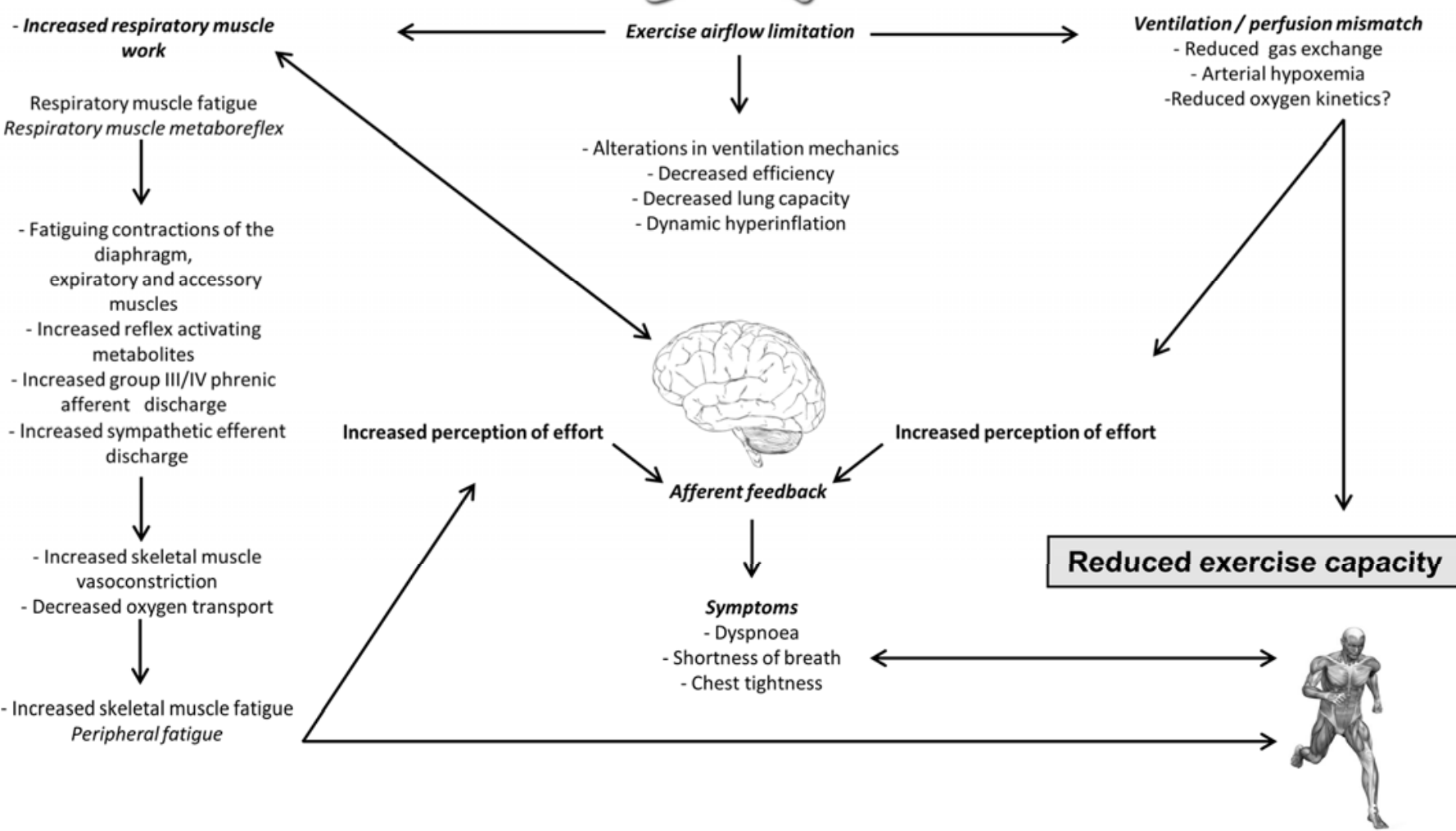

Figure 2. 

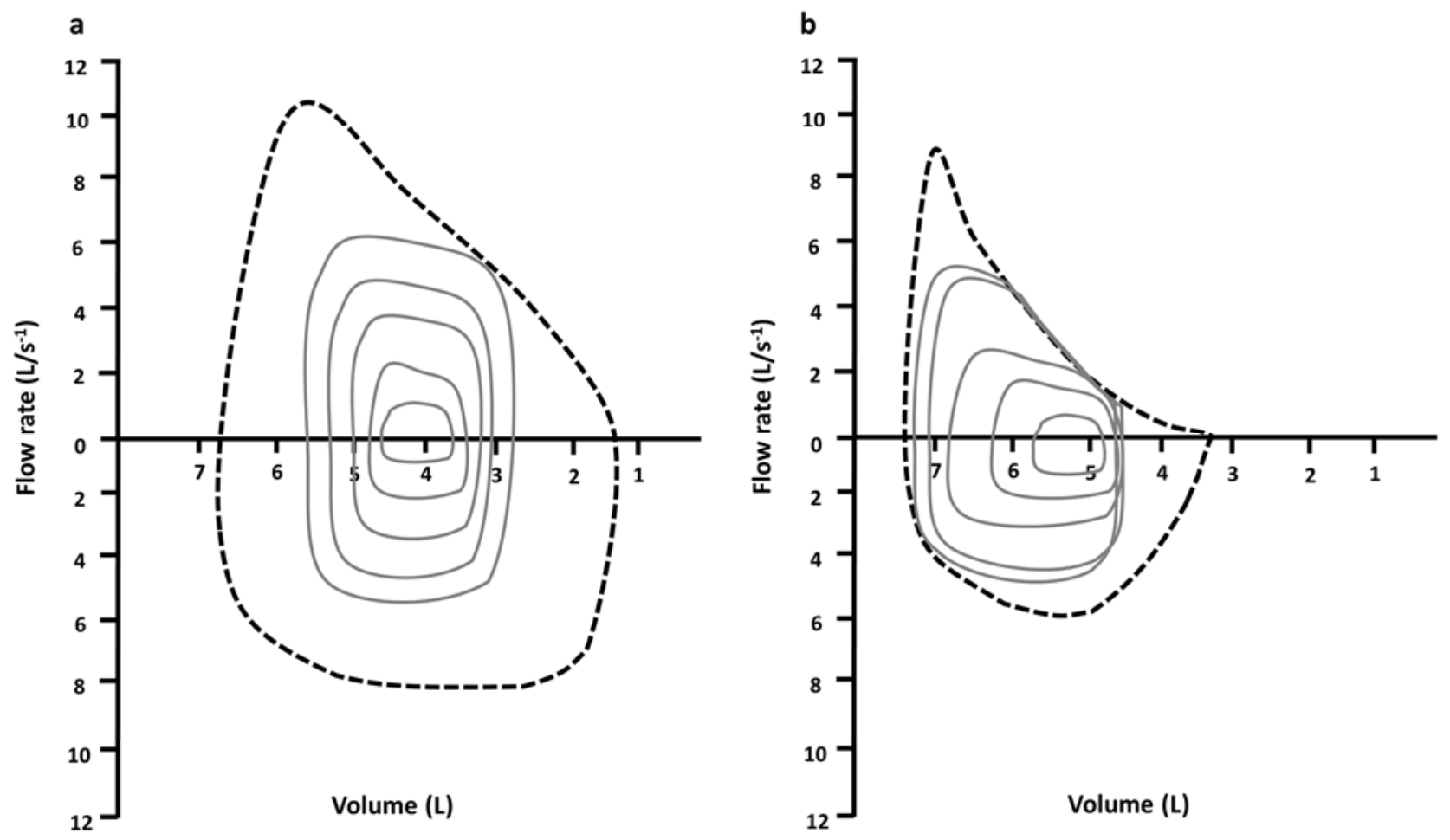

Figure 3. 


\section{ACKNOWLEDGEMENTS}

No sources of funding were used to assist in the preparation of this review. The authors have no real or perceived conflict of interest in respect of the content of this review. The manuscript does not contain clinical studies of patient data. All authors contributed to the preparation of this manuscript. 


\section{REFERENCES}

1. IOC. http://www.olympic.org/olympic-results/london-2012/athletics. 2012.

2. Bassett JR DR, Howley ET. Limiting factors for maximum oxygen uptake and determinants of endurance performance. Med Sci Sports Exerc. 2000;32(1):70-84.

3. Dempsey JA. JB Wolffe memorial lecture. Is the lung built for exercise? Med Sci Sports Exerc. 1986;18(2):143-55.

4. Price OJ, Ansley L, Menzies-Gow A, et al. Airway dysfunction in elite athletes-an occupational lung disease? Allergy. 2013;68(11):1343-52.

5. Weiler JM, Bonini S, Coifman R, et al. American Academy of Allergy, Asthma \& Immunology Work Group report: exercise-induced asthma. J Allergy Clin Immunol. 2007;119(6):1349-58.

6. Haahtela T, Malmberg P, Moreira A. Mechanisms of asthma in Olympic athletespractical implications. Allergy. 2008;63(6):685-94.

7. McKenzie DC, Fitch KD. The asthmatic athlete: inhaled beta-2 agonists, sport performance, and doping. Clin J Sport Med. 2011;21(1):46-50.

8. Fitch KD. An overview of asthma and airway hyper-responsiveness in Olympic athletes. Br J Sports Med. 2012;46(6):413-6.

9. Price OJ, Hull JH. Asthma in elite athletes: Who cares? Clin Pulmonary Med. 2014;21(2):68-75.

10. Stickland MK, Rowe BH, Spooner CH, et al. Effect of warm-up exercise on exerciseinduced bronchoconstriction. Med Sci Sports Exerc. 2012;44(3):383-91.

11. Teixeira RN, Teixeira LR, Costa LAR, et al. Exercise-induced bronchoconstriction in elite long-distance runners in Brazil. J Bras Pneumol 2012;38(3):292-8.

12. Sonna LA, Angel KC, Sharp MA, et al. The prevalence of exercise-induced bronchospasm among US army recruits and its effects on physical performance. Chest. 2001;119(6):1676-84.

13. Freeman W, Nute M, Brooks S, et al. Responses of asthmatic and non-asthmatic athletes to prolonged treadmill running. Br J Sports Med. 1990;24(3):183-90.

14. Freeman W, Williams C, Nute M. Endurance running performance in athletes with asthma. J Sports Sci. 1990;8(2):103-17.

15. Stensrud T, Berntsen S, Carlsen K-H. Exercise capacity and exercise-induced bronchoconstriction (EIB) in a cold environment. Respir Med. 2007;101(7):1529-36.

16. Stensrud T, Berntsen S, Carlsen KH. Humidity influences exercise capacity in subjects with exercise-induced bronchoconstriction (EIB). Respir Med. 2006;100(9):1633-41. 
17. Steinshamn S, Sandsund M, Sue-Chu M, et al. Effects of montelukast on physical performance and exercise economy in adult asthmatics with exercise-induced bronchoconstriction. Scand J Med Sci Sports. 2002;12(4):211-7.

18. Steinshamn S, Sandsund M, Sue-Chu M, et al. Effects of montelukast and salmeterol on physical performance and exercise economy in adult asthmatics with exercise-induced bronchoconstriction. Chest. 2004;126(4):1154-60.

19. Freeman W, Packe G, Cayton R. Effect of nebulised salbutamol on maximal exercise performance in men with mild asthma. Thorax. 1989;44(11):942-7.

20. Koch S, MacInnis MJ, Sporer BC, et al. Inhaled salbutamol does not affect athletic performance in asthmatic and non-asthmatic cyclists. $\mathrm{Br} J$ Sports Med. 2013;doi:10.1136/bjsports-2013-092706.

21. Guyatt GH, Oxman AD, Schünemann HJ, et al. GRADE guidelines: A new series of articles in the Journal of Clinical Epidemiology. Journal of clinical epidemiology. 2011;64(4):380-2.

22. McNicholl DM, Megarry J, McGarvey LP, et al. The utility of cardiopulmonary exercise testing in difficult asthma. Chest. 2011;139(5):1117-23.

23. Kukafka DS, Ciccolella D, D'Alonzo Jr GE, et al. Exercise-induced bronchospasm in high school athletes via a free running test. Chest. 1998;114(6):1613-22.

24. Medelli J, Lounana J, Messan F, et al. Testing of pulmonary function in a professional cycling team. J Sports Med Phys Fitness. 2006;46(2):298-306.

25. Patton JF, Vogel JA. Effects of acute cold exposure on submaximal endurance performance. Med Sci Sports Exerc. 1984;16(5):494-7.

26. Kippelen P, Bolger C, Malatesta D, et al. Does exercise-induced bronchoconstriction affect oxygen uptake kinetics in athletes? 15th Annual Congress of the European College of Sport Science; 2010; Antalya, Turkey.; 2010.

27. Legaz-Arrese A, Munguía-Izquierdo D, Nuviala Nuviala A, et al. Average VO2max as a function of running performances on different distances. Sci Sports. 2007;22(1):43-9.

28. Dickinson J, Hu J, Chester N, et al. The physiological effect of $800 \mathrm{mcg}$ and $1600 \mathrm{mcg}$ inhaled salbutamol during a football specific treadmill run at high ambient temperatures. $\mathrm{Br} \mathrm{J}$ Sports Med. 2011 December 1, 2011;45(15):A19-A20.

29. Hull J, Conlon J, Gateley B, et al. Does salbutamol improve athletic performance in elite soccer players with EIB? C22. Asthma therapy: American Thoracic Society; 2012. p. A3969-A.

30. Kalsen A, Hostrup M, Bangsbo J, et al. Combined inhalation of beta2-agonists improves swim ergometer sprint performance but not high - intensity swim performance. Scand J Med Sci Sports. 2013;doi: 10.1111/sms.12096. 
31. Crimi E, Pellegrino R, Smeraldi A, et al. Exercise-induced bronchodilation in natural and induced asthma: effects on ventilatory response and performance. J Appl Physiol. 2002;92(6):2353-60.

32. Haverkamp H, Dempsey J, Miller J, et al. Gas exchange during exercise in habitually active asthmatic subjects. J Appl Physiol. 2005;99(5):1938-50.

33. Kosmas E, Milic-Emili J, Polychronaki A, et al. Exercise-induced flow limitation, dynamic hyperinflation and exercise capacity in patients with bronchial asthma. Eur Respir J. 2004;24(3):378-84.

34. Calverley P. Exercise and dyspnoea in COPD. Eur Respir Rev. 2006;15(100):72-9.

35. Aaron E, Seow K, Johnson B, et al. Oxygen cost of exercise hyperpnea: implications for performance. J Appl Physiol. 1992;72(5):1818-25.

36. Vella CA, Marks D, Robergs RA. Oxygen cost of ventilation during incremental exercise to VO2 max. Respirology. 2006;11(2):175-81.

37. Dempsey JA, Romer L, Rodman J, et al. Consequences of exercise-induced respiratory muscle work. Respir Physiol Neurobiol. 2006;151(2-3):242-50.

38. Harms CA, Wetter TJ, Croix CMS, et al. Effects of respiratory muscle work on exercise performance. J Appl Physiol. 2000;89(1):131-8.

39. Parshall MB, Schwartzstein RM, Adams L, et al. An official American Thoracic Society statement: update on the mechanisms, assessment, and management of dyspnea. Am J Respir Crit Care Med. 2012;185(4):pp. 435-52.

40. Noakes TD. Linear relationship between the perception of effort and the duration of constant load exercise that remains. J Appl Physiol. 2004;96(4):1571-3.

41. Caeauelli E, J Nobel BJ. The effect of inspired carbon dioxide on subjective estimates of exertion during exercise. Ergonomics. 1976;19(5):581-9.

42. Widdicombe J. Lung afferent activity: implications for respiratory sensation. Respir Physiol Neurobiol. 2009;167(1):2-8.

43. Nishino $\mathrm{T}$. Dyspnoea: underlying mechanisms and treatment. $\mathrm{Br} \mathrm{J}$ Anaesth. 2011;106(4):463-74.

44. Moxham J, Jolley C. Breathlessness, fatigue and the respiratory muscles. Clin Med. 2009;9(5):448-52.

45. Goubault C, Perault M, Leleu E, et al. Effects of inhaled salbutamol in exercising nonasthmatic athletes. Thorax. 2001;56(9):675-9.

46. Dempsey JA, Wagner PD. Exercise-induced arterial hypoxemia. J Appl Physiol. 1999;87(6):1997-2006. 
47. Muñoz PA, Gómez FP, Manrique HA, et al. Pulmonary gas exchange response to exercise-and mannitol-induced bronchoconstriction in mild asthma. J Appl Physiol. 2008;105(5):1477-85.

48. Parsons JP, Hallstrand TS, Mastronarde JG, et al. An official American Thoracic Society clinical practice guideline: exercise-induced bronchoconstriction. Am J Respir Crit Care Med. 2013;187(9):1016-27.

49. Bonini M, Di Mambro C, Calderon MA, et al. Beta-2 agonists for exercise induced asthma. The Cochrane Library. 2009;10.1002/14651858.CD003564.pub3.

50. Bedi J, Gong Jr H, Horvath S. Enhancement of exercise performance with inhaled albuterol. Can J Sport Sci. 1988;13(2):144-8.

51. Kindermann W. Do inhaled beta(2)-agonists have an ergogenic potential in nonasthmatic competitive athletes? Sports Med. 2007;37(2):95-102.

52. Pluim BM, de Hon O, Staal JB, et al. $\beta 2$-agonists and physical performance. Sports Med. 2011;41(1):39-57.

53.WADA.http://www.wadaama.org/Documents/World_AntiDoping_Program/WADPProhib itedlist/To_be_effective/WADA_Prohibited_List_2011_EN.pdf.

54. Sporer BC, Sheel AW, McKenzie DC. Dose response of inhaled salbutamol on exercise performance and urine concentrations. Med Sci Sports Exerc. 2008;40(1):149-57.

55. Van Baak M, De Hon O, Hartgens F, et al. Inhaled salbutamol and endurance cycling performance in non-asthmatic athletes. Int J Sports Med. 2004;25(7):533-8.

56. Decorte N, Bachasson D, Guinot M, et al. Impact of salbutamol on neuromuscular function in endurance athletes. Med Sci Sports Exerc. 2013;45(10):1925-32.

57. Ingemann-Hansen $\mathrm{T}$, Bundgaard A, Halkjær-Kristensen $\mathrm{J}$, et al. Maximal oxygen consumption rate in patients with bronchial asthma-the effect of $\beta 2$-adrenoreceptor stimulation. Scand J Clin Lab Invest. 1980;40(2):99-104.

58. Dickinson J, Molphy J, Chester N, et al. The ergogenic effect of long-term use of high dose salbutamol. Clin J Sport Med. 2014;doi: 10.1097/JSM.0000000000000076.

59. Dickinson J, Hu J, Chester N, et al. Acute impact of inhaled short acting B2-agonists on $5 \mathrm{Km}$ running performance. J Sports Sci Med. 2014;13(2):271-9.

60. Caruso JF, Hamill JL, De Garmo N. Oral albuterol dosing during the latter stages of a resistance exercise program. J Strength Cond Res. 2005;19(1):102-7.

61. Elers J, Pedersen L, Henninge J, et al. The pharmacokinetic profile of inhaled and oral salbutamol in elite athletes with asthma and nonasthmatic subjects. Clin J Sport Med. 2012;22(2):140-5. 
62. Hull J, Ansley L, Garrod R, et al. Exercise-induced bronchoconstriction in athletesshould we screen? Med Sci Sports Exerc. 2007;39(12):2117 - 24.

63.www.olympic.org/Documents/Reports/EN/en_report_1302.pdf TIOC. World AntiDoping Agency.TheInternationalOlympicCommittee:www.olympic.org/Documents/Reports/EN/en_r eport_1302.pdf 2008. 